\title{
Supermercados 'Vegan Friendly'. A propósito de Mercadona
}

Keywords: veganismo; vegan friendly; consumo; derecho animal

Tiene que ver con lo que comemos. Es claro que no tomar alimentos que procedan de animales es una decisión personal, pero no sólo. También tiene que ver con lo que queremos que sea de nuestro entorno, con el respeto con el que nos conducimos con la naturaleza y con el compromiso que adoptamos en nuestra conducta como ciudadanos. Por tanto, ser vegetariano o vegano tiene -por lo menos- un ámbito tridimensional: personal, ambiental, político.

Los supermercados de proximidad en España, raramente exhiben en sus lineales alimentos que puedan ser consumidos, por quienes no quieren comer productos procedentes de animales. Por ello, que Mercadona haya anunciado el lanzamiento de una línea de charcutería "Vegan Friendly", ha saltado como noticia destacada en plena canícula estival. En realidad, se trata -de momento-, de unos pocos productos que no siendo estrictamente veganos, sí son accesibles para vegetarianos y flexiterianos. Por algo se empieza, bienvenida esta iniciativa!.

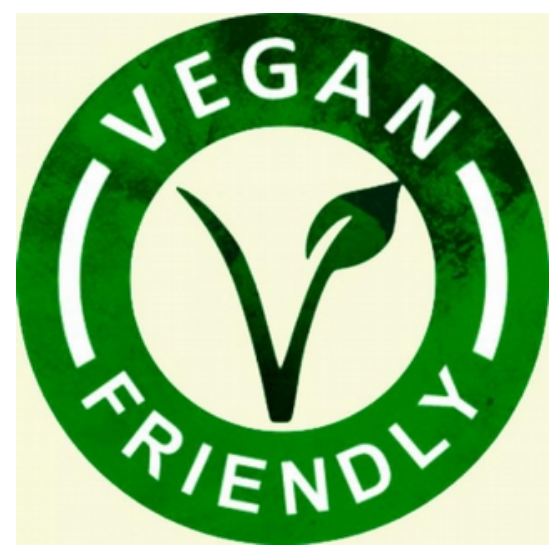

Hace reflexionar que para comprar productos veganos haya que rebuscar en tiendas, que, normalmente, se encuentran de momento en las grandes ciudades y son difíciles de encontrar en las ciudades medias y en los pueblos de España. En este sentido, poco nos asemejamos a otros países de nuestro entorno como Reino Unido, Francia, Suiza, Austria o Alemania[1], que tienen una larga tradición de venta de productos aptos para veganos. Hay webs y apps que, de forma sencilla, informan del contenido de los productos de consumo normal en los supermercados. Sobre ello nos pronunciamos hace un año, través de un excelente artículo publicado en la web por Martina Pluda, que recomiendo releer. Decididamente, esto aún no pasa por aquí.

Cuando lo que consumimos son animales, la cuestión se amplía a ámbitos que se aproximan a la ética personal y política. Un aspecto que no ha pasado inadvertido a la comunidad científica y ya ha sido objeto de discusión[2] y de informes[3] que alertan sobre la responsabilidad del bienestar animal que, como ciudadanos, nos concierne. Aunque los resultados, a día de hoy, confirman que los consumidores europeos sí empezaron a preocuparse -ya en el año 2000- por el bienestar de los animales que consumen, dicha preocupación no es aún una prioridad a la hora de elegir qué se va a consumir. En mi opinión, por ausencia de la adecuada información. 


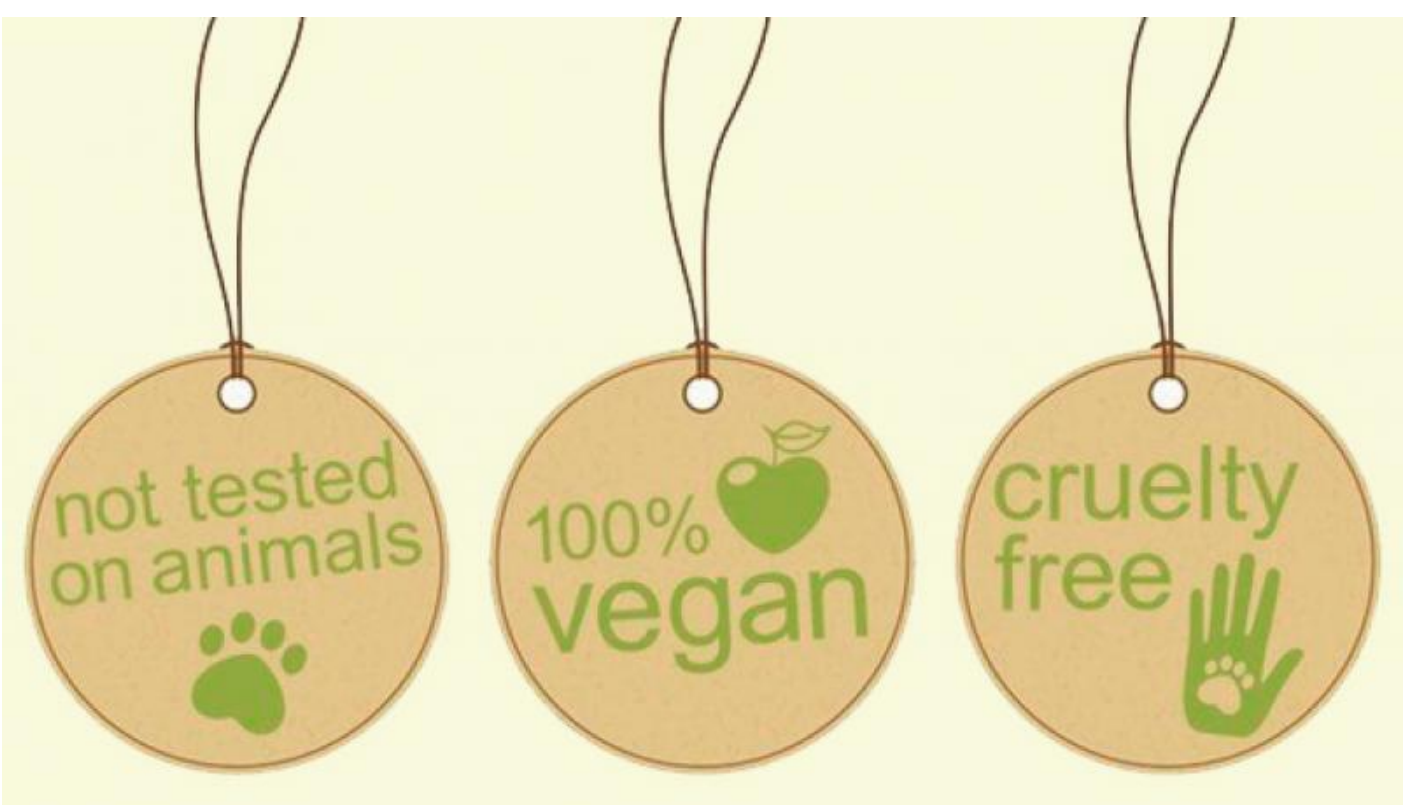

Lo que sí es cierto es que después de 16 años de políticas informativas de la UE, los parámetros de elección de los consumidores han cambiado de forma apreciable. Hoy se demanda mayor transparencia en lo que se compra en el supermercado, pues se relaciona la calidad del producto, con el origen y el bienestar del animal que lo haya producido. Un ejemplo palpable son los huevos, a los que en su momento ya hice referencia[4]. Los consumidores sabemos hoy qué quiere decir el código de barras de los huevos y podemos elegir -si es que los consumimos-, entre huevos de gallinas camperas o de gallinas que viven hacinadas en "battery cages". Cuestión de información, de sensibilización social, de transparencia comunicativa y, en definitiva, de etiquetaje.

Entre las estrategias de la UE que han contado con más éxito, se señalan las que, en los últimos años han propugnado un mejor conocimiento del bienestar animal, una mejora de las condiciones de vida de los animales y la búsqueda de la complicidad de los consumidores[5]. No hay más que echar un vistazo a cómo se han transformado los nombres de los locales de comidas (los Bares son hoy "Gastro-Bares"!), se han incrementado los restaurantes veganos y en la oferta de los cartas de restaurante - incluso en las cafeterías de los locales de trabajo- empiezan a señalarse aquellos platos accesibles para veganos y vegetarianos.

\section{Código de forma de cria:}

$0=$ Producción ecolbgica (gallinas libres y alimentadas a base de piensos ecolbgicos)

$1=$ Gallinas camperas (libres y alimentadas con piensos tradicionales)

$2=$ Gallinas de suelo (hacinadas horizontalmente)

3- Gallinas enjauladas (hacinadas verticalmente)

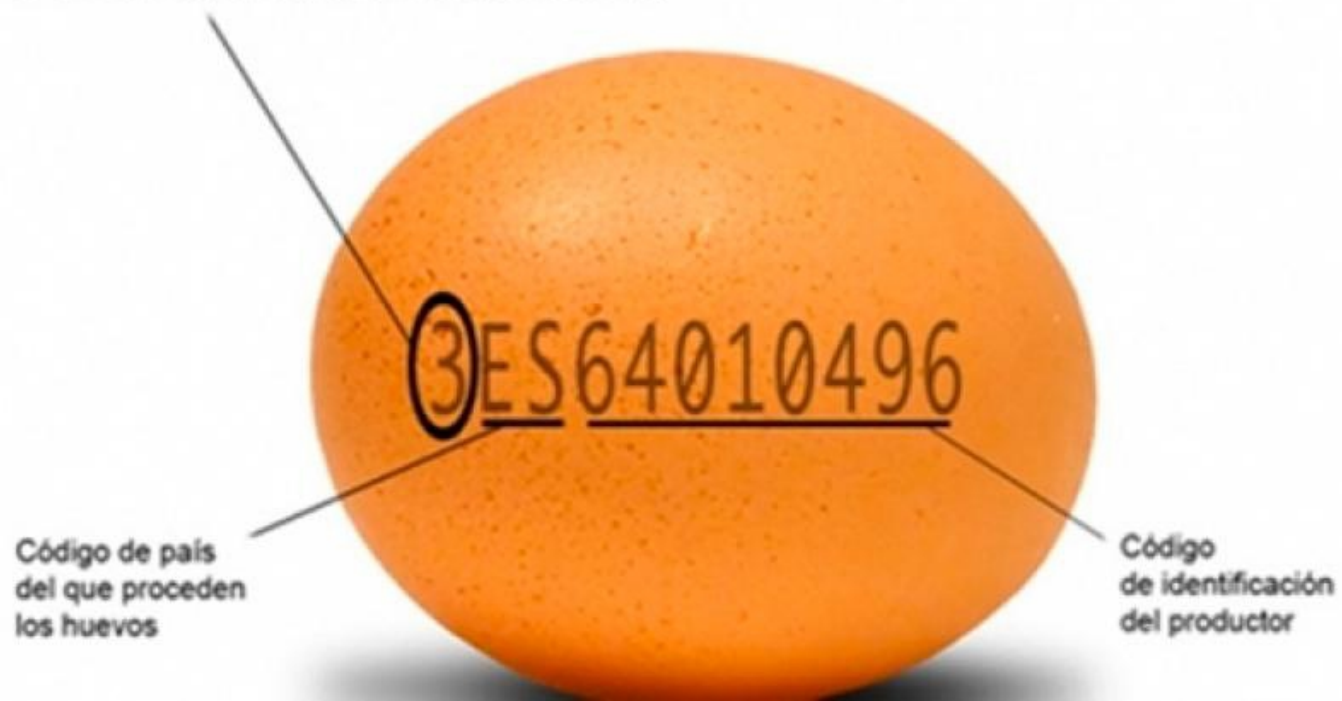


Sin embargo, queda un largo recorrido por hacer y estamos al principio. Las iniciativas, como la que ha lanzado Mercadona, tienen que multiplicarse y llegar a todos los consumidores en cualquier rincón de España, con toda la información que se requiere. La sociedad se ha transformado, pero carecemos de políticas públicas que se adapten a este cambio. Una vez más, somos la gente de a pie, los consumidores corrientes, los que, con un pequeño gesto: elegir no comer animales y elegir el respeto en la crianza de los mismos (para los que consumen animales), marcamos la diferencia.

LA EDITORA

Teresa Giménez-Candela

Catedrática de Derecho Romano

Directora del Master en Derecho Animal y Sociedad

Directora del ICALP

Universitat Autònoma de Barcelona

Sígueme en Facebook: https://www.facebook.com/editora.da

[1] Vid. la crónica sobre Berlín vegano de nuestra responsable de comunicación, Krizia Said, durante sus prácticas curriculares en PETA Deutschland.

[2] MIELE, M. and EVANS, A. (2010) 'When foods become animals: Ruminations on Ethics and

Responsibility in Care-full practices of consumption', Ethics, Place \& Environment, 13: 2, $171-190$.

[3] HARPER, G. and SPENCER H., Consumer Concerns about Animal Welfare and the Impact on Food Choice.

[4] GIMÉNEZ-CANDELA-M., Cuestión de huevos.

[5] EU Animal Welfare Strategy: 2012-2015. Better Welfare for Animals. A new Strategy for a new Approach: "European citizens care deeply about animal welfare, ans in recent years more and more people become concerned about the ethical treatment of animals. Thanks to the European Union's Lisbon Treaty, animals are recognised as sentient beings, meaning that they are capable of feeling pleasure and pain. In recognition of this, the European Commission has adopted a new strategy to improve welfare conditions for animals kept on farms, living in zoos and used for experiments. The European Commission is striving to ensure that farm animals are kept and transported under conditions that do not subject them to maltreatment, abuse, pain or suffering". 